\title{
MIXED ARTERIO-VENOUS INSUFFICIENCY IN RANDOM SKIN FLAPS \\ IN THE RAT: IS THE APPLICATION OF MEDICINAL LEECHES BENEFICIAL?
}

Schlaudraff K.-U. MD, Bezzola T. MD, Montandon D. MD, Pepper M.S.* MBChB PhD MD, Pittet B. MD

Plastic and Reconstructive Surgery Unit, Department of Surgery, University Hospitals of Geneva, Geneva, Switzerland

* Netcare Institute of Cellular and Molecular Medicine, Unitas Hospital, Lyttelton, and Department of Immunology, Faculty of Health Sciences, University of Pretoria, South Africa

Submitted to: Journal of Surgical Research, JSR category: Wound Healing/Plastic Surgery

Running head: Leech application in AV-insufficient flaps

Preliminary results were presented at the European Conference of Scientists and Plastic Surgeons 2002 in Vienna, Austria:

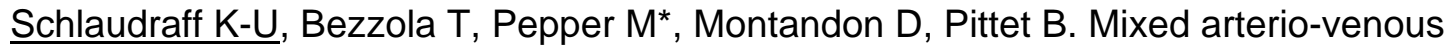
insufficiency in a random dorsal skin flap model in the rat: Is the application of medicinal leeches beneficial?

The study was supported by grants from the Swiss National Science Foundation: grant no: 3200-067254.01 to B. Pittet and grant no: 3100-064037.00 to M.S. Pepper.

Corresponding author

Prof. B. Pittet

Plastic and Reconstructive Surgery Unit

Department of Surgery

University Hospitals of Geneva

Rue Micheli-du-Crest 24

CH-1211 Geneva 14 / Switzerland

Tel: +41-22-3727997 Fax: +41-22-3728004

Email: Brigitte.Pittet-Cuenod@hcuge.ch 


\section{ABSTRACT}

Background: Leeches are commonly used in reconstructive surgery for the treatment of venous congestion in flaps. Documented mechanisms of action are: 1) injection of the anticoagulant hirudin; 2) active suction of blood; and 3) passive oozing of the bite wound. Even though the benefits of leeches in venous congestion are widely accepted, little is known about their effects in mixed arterio-venous insufficiency.

Methods: 30 Wistar rats were randomized into 3 groups ( $n=10$ each) and $9 \times 3 \mathrm{~cm}$ ischemic random skin flaps were elevated on the rat dorsum. Group 1 served as controls. In group 2, one leech was applied to the distal part of the flap and in group 3, three leeches were applied, one at a time, at 8 hour intervals. Postoperatively, flap survival and perfusion were quantitated by daily planimetry and Laser-Doppler imaging.

Results: The application of a single leech on postoperative day 7 did not lead to any statistically significant changes in total flap survival or tissue perfusion. Triple leech application, however, caused a significant decrease in flap survival of $6.6 \%$ at day 7 (3x leech vs. control: $45.8 \pm 8.5 \%$ vs. $52.4 \pm 8.5 \%$, respectively) $(p<0.01)$ and a decline in flap perfusion of $13 \%$ ( $3 x$ leech vs. control: $71.3 \pm 16.6 \%$ vs. $84.3 \pm 9.3 \%$, respectively) $(p<0.01)$.

Conclusion: The data demonstrate that the application of leeches in the setting of mixed arterio-venous insufficiency can be hazardous to flap viability. Pure venous congestion with an adequate arterial supply remains the only indication for controlled leech application in the clinical setting.

Keywords: ischemia, venous congestion, Hirudo medicinalis, arterio-venous insufficiency, bloodletting, skin/blood supply, skin/pathology 
August 14th 2007

\section{INTRODUCTION}

"Random" skin flaps are frequently used to reconstruct tissue defects of small or medium size $(1,2)$ e.g., after trauma or tumor surgery $(3,4)$. They are characterized by the absence of a vascular pedicle and tissue perfusion relies entirely on a randomly distributed vascular network. Signs of "randomization" may also be observed in peripheral areas of "axial" flaps whenever their design exceeds the defined limitations of the underlying arteriosome/venosome and therefore includes tissue that is not directly perfused by the flap's pedicle vessels. For this reason, a less-than-optimal design of "random" as well as "axial" flaps may lead to peripheral arterio-venous insufficiency and finally to partial flap necrosis that may jeopardize the success of the reconstructive procedure. Unlike pure "axial" flaps in which flap failure is usually due to problems with the vascular pedicle, arterio-venous insufficiency in "random" or randomized "axial" flaps is the result of progressive microcirculatory disturbances. These are caused either by an initial decrease in arterial inflow and subsequent venous stasis, or by a primary increase in venous outflow resistance that progressively alters the arterial hemodynamics. Initially, venous congestion causes an increase in interstitial pressure, edema, as well as hemoconcentration, and a secondary slowing of the capillary blood flow. The subsequent microthrombosis then results in arterial insufficiency and may lead finally to flap ischemia or even necrosis (5-8).

In the quest for alternative salvage procedures for imminent flap failure, one of the oldest medical practices has been re-discovered (9-11) - the letting of blood, achieved by the application of leeches (12-14). In historical reports, leeches were used for their superb decongestant properties $(15,16)$ and were empirically applied whenever surgeons faced pronounced venous insufficiency (17-19). The most commonly used leech is Hirudo medicinalis, a freshwater hermaphrodite, which was chosen primarily for its ability to inflict the deepest bite and to cause the most prolonged period of post-bite blood oozing (20). The therapeutic benefit of leeches is a combination of 1 ) the injection of a salivary cocktail of anticoagulants into the dermis that stimulates and perpetuates local blood flow $(21,22), 2)$ the mechanical effect of active suction of blood from the flap with a negative pressure of up to $1 / 10 \mathrm{~atm}(23,24)$, and 3 ) the passive oozing of the bite wound after leech detachment $(20,25)$. The application of leeches thus allows the evacuation of venous blood from engorged flaps and results in a temporary restoration of the capillary blood flow as well as improved tissue viability $(26,27)$. Thus far, the application of leeches has only been described in the clinical setting of severe venous congestion $(8,28)$ or the complete absence of venous drainage in "axial" flaps $(20,29)$, replanted ears $(30,31)$ or digits $(32,33)$. However, the pathophysiology of mixed arterio-venous 
insufficiency in failing "random" flaps, as well as the effects of the application of leeches in this setting remain poorly understood.

In the present study in the rat, we investigated whether the application of leeches could increase the total survival of arterio-venous insufficient random dorsal skin flaps. We hypothesized that the mechanical suction of blood by the leech may not only reduce venous congestion but also promote arterial inflow in the ischemic tissue and that the anticoagulants of the leeches' saliva may inhibit microthrombosis in the ischemic part of the flap, thereby maintaining local microcirculation.

\section{METHODS}

\section{Animals}

The present study was approved by the ethics committee of the University of Geneva as well as the local veterinary authorities in accordance with Swiss guidelines. Male Wistar rats weighing 250-300g were housed individually at room temperature with a 12-h day/night cycle and water and food ad libitum. A total of 30 animals were randomly assigned to control or study groups of 10 rats each and elevation of a random dorsal skin flap was performed as described below: group 1 served as controls (no leech); in group 2, we performed a single leech application at $5 \mathrm{~min}$ postoperatively (single leech); and group 3 underwent a leech application at $5 \mathrm{~min}$, $8 \mathrm{~h}$ and 16h after flap elevation (triple leech).

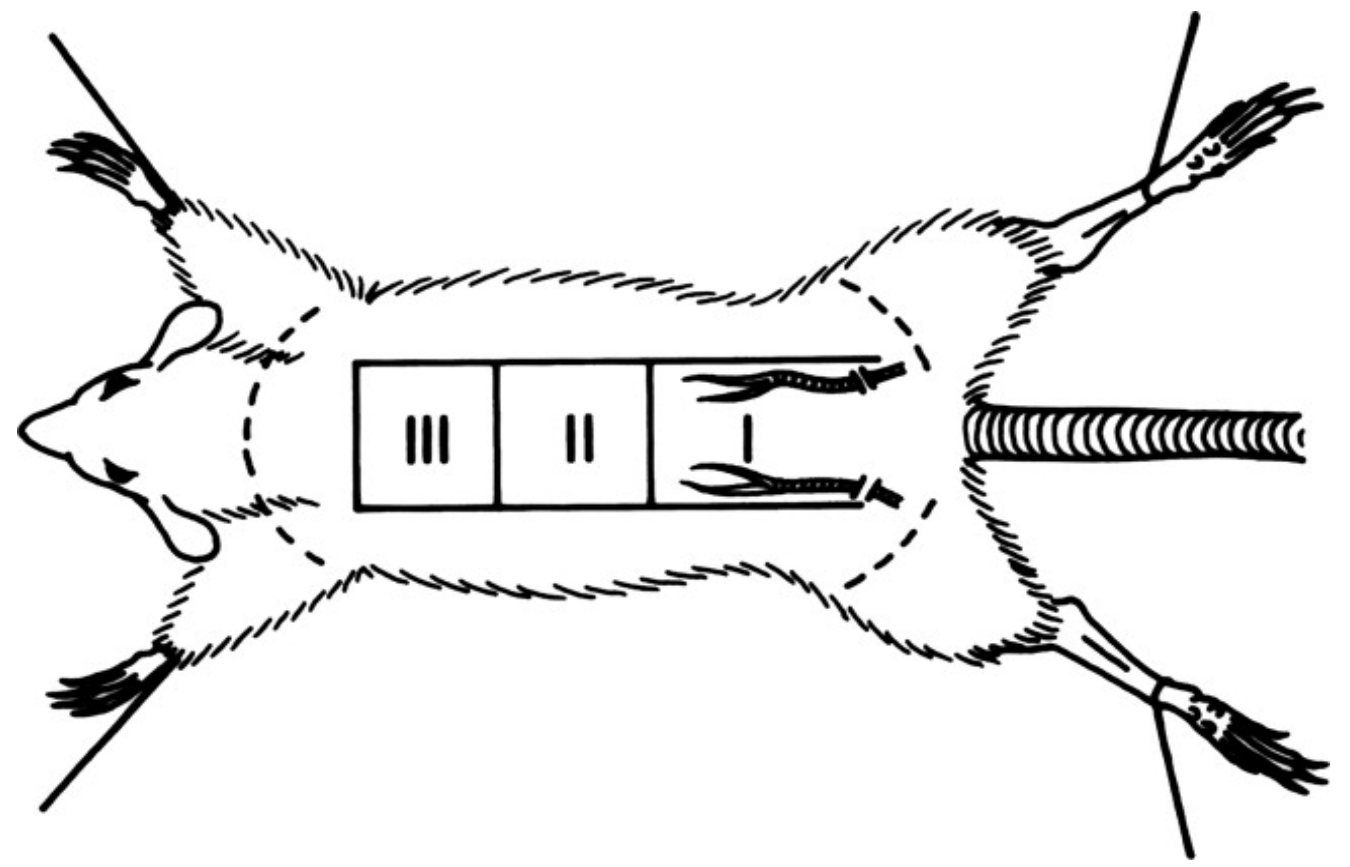

Figure 1: Schematic representation of a random dorsal skin flap in the rat $(9 \times 3 \mathrm{~cm})$ divided into proximal (I), intermediate (II) and distal (III) areas. Note that during flap elevation both sacral arteries were sectioned (36). 


\section{Flap elevation}

For surgical procedures, rats were anesthetized by non-assisted inhalation of $2 \%$ isoflurane (Abott AG, Baar, Switzerland) and rectal temperature was maintained at $34^{\circ} \mathrm{C}$. Prior to surgery, the entire rat dorsum was shaved and chemically depilated. The skin was thoroughly washed with soap and water and rinsed with non-chlorinated water to remove any remnants of depilating cream or repelling odors. Random dorsal skin flaps were elevated using the model initially described by McFarlane (34) and later modified by Rinsch et al (35). We outlined caudallybased, $9 \times 3 \mathrm{~cm}$ large skin/panniculum carnosum flaps on the back of the rats and systematically sectioned both sacral arteries. The flaps were immediately sutured back onto their original anatomic site. For analysis, the flap area was divided into three distinct zones of equal size reflecting the clinical aspect of complete flap survival in the proximal area I, a mixed pattern of flap survival and partial necrosis in the intermediate area II, and full thickness necrosis in the distal area III (figure 1) (36).

\section{Leech application}

Fasting leeches were provided by the pharmacy of the University Hospitals of Geneva in a cloth-covered container and stored in a solution of distilled water and Hirudo Salt (Leeches USA) in the dark at $7^{\circ} \mathrm{C}$. Before use, the leeches' initial weight was noted and immediately after surgical flap elevation, leeches were allowed to attach in the center of the distal part of the flap (area III) and to feed at will while the rats were still anesthetized. After spontaneous release, leeches were weighed again and total weight gain was converted to $\mathrm{ml}$ of blood $(\mathrm{g}$ of weight gain equals $1 \mathrm{ml}$ of blood) (37). In group 2, one leech was allowed to feed in the distal part of the flap and in group 3, a triple application of one leech at a time was performed at $8 \mathrm{~h}$ intervals. The rats in group 1 (control group) were not treated with leeches. All rats were anesthetized for either the leech application or the sham session and then put back into their cages for recovery.

\section{Macroscopic and planimetric analysis}

Macroscopic and planimetric analysis was carried out daily during a two-week period. The rats' dorsum was photographed with a Nikon Coolpix 4500. For planimetry, the margins of the flap and the area of necrosis were traced on transparent acetate sheets. Both surfaces were quantitated with a polar planimeter and flap survival was measured by subtracting the area of necrosis from the total flap surface. Results were expressed as percentage values and represent the average of three measurements. 
August 14th 2007

\section{Laser-Doppler flowmetry}

During a two-week period, daily skin perfusion analysis was carried out using a percutaneous Laser-Doppler perfusion imager (Derma PIM II, Lisca AB, Linköping, Sweden). The LaserDoppler unit scanned the entire surface of the skin flap and the surrounding tissue of the rat's back. Cutaneous blood flow was expressed in arbitrary perfusion units (PU) and encoded in a color-graded image. Quantification was carried out with Patchtest-Wizard 1.2 software (Lisca $A B)$ and regions of interest were outlined according to the three predefined areas of the flap (36). As a reference value, blood flow in normally perfused skin was measured in two regions localized laterally to the flap. Blood flow at areas I, II and III was expressed as the percentage of mean perfusion of normal skin. Final values represent the average values of three measurements.

\section{Statistical methods}

Statistical analysis of the data was performed using Fisher's ANOVA computed on GraphPad's Instat 3.0 software after a standard normality test. All values are expressed as mean $\pm \mathrm{sd}$. The significance level was established at $p<0.05$.

\section{Results}

\section{Leech application:}

After elevation of the random dorsal skin flap, leech attachment was obtained without difficulty in all animals of experimental groups 2 and 3. Feeding activity was normal until spontaneous release after engorgement and feeding time averaged $72 \pm 22 \mathrm{~min}(n=40)$. Average weight gained by the feeding leech was $0.91 \pm 0.17 \mathrm{~g}$ and mean oozing time from each leech bite averaged $188 \pm 52 \mathrm{~min}$. None of the rats were exsanguinated by leeching nor did we encounter any problems of scratching/biting the fresh bite sites. No signs of adverse reactions due to the leech application were observed.

\section{Macroscopic analysis}

After random dorsal skin flap elevation, distal perfusion was initially maintained, as indicated by continuous arterial bleeding from the borders of the flap. Within the first $12 \mathrm{~h}$ postoperatively, we noted a purple discoloration, an increase in tissue edema and cessation of peripheral bleeding of the distal flap area III - i.e. signs of progressive arterio-venous insufficiency.

At baseline, venous congestion/edema was similar in all three study groups. After a single leech application tissue edema in the distal part of the flap was visibly reduced when compared to the control animals. However, in both the control and the single leech group, development of tissue 
necrosis started simultaneously at postoperative day 2 with superficial epidermolysis in the most distal part of the flap that progressively extended more proximally. Full thickness necrosis, indicated by the appearance of a black scab, was fully established in area III at postoperative day 4.

After the triple leech application, tissue edema was visibly less when compared to the control and single leech group and flaps showed only a little purple discoloration. Progressive arterial insufficiency due to an overly pronounced withdrawal of blood was rapidly indicated by dark red and black spots in the distal area III - indicative of early epidermolysis. We also observed the precocious development of flap necrosis that was already present when the last leech was applied (at 16h postoperatively) and located at the site of the leech bites. Full thickness necrosis in the distal area III was already fully established at postoperative day $2(p<0.01)$ (figure 2$)$.

\section{Flap survival}

At postoperative day 7, planimetric analysis in the control group showed an average survival rate of $52.4 \pm 8.5 \%$ of the total flap surface. The application of a single leech (group 2 ) did not lead to any statistically significant changes: at day 7 , total flap survival was $52.7 \pm 6.4 \%$ in the single leech group vs. $52.4 \pm 8.5 \%$ in the control group. However, triple leech application lead to a decrease in total flap survival by $6.6 \%(p<0.01)$ : at postoperative day 7 , flap survival in this group was $45.8 \pm 8.5 \%$ vs. $52.4 \pm 8.5 \%$ in the control group (figure 3 ).

\section{Laser-Doppler flowmetry}

At day 2 after elevation of the random skin flap in control animals, Laser-Doppler measurements showed a flap perfusion of $93.2 \pm 16.5 \%$ of normal cutaneous values in the proximal area I and of $57.2 \pm 10.3 \%$ of normal skin perfusion in area II. After a single leech application (group 2) LaserDoppler flowmetry revealed a significant increase in blood flow in the proximal area I of 9\% (1x leech vs. control: $102.2 \pm 13.2 \%$ vs. $93.2 \pm 16.5 \%$, respectively) and in area II of $15.2 \%$ (1x leech vs. control: $72.4 \pm 9.1 \%$ vs. $57.2 \pm 10.3 \%$, respectively) $(p<0.01)$. After the triple leech application, flap perfusion remained unchanged in area I (3x leech vs. control: $92.7 \pm 16.7 \%$ vs. 93.2 $\pm 16.5 \%$, respectively) and was increased by $2.3 \%$ in the intermediate area II (3x leech vs. control: $59.5 \pm 8.5 \%$ vs. $57.2 \pm 10.3 \%$, respectively), but values did not reach statistical significance $(p<0.064)$. Measurements in area III, the distal part of the flap, were not considered since the leeches' bitemarks and the early superficial epidermolysis impaired reliable perfusion analysis. However, immediately after flap elevation, Laser Doppler flowmetry showed a blood perfusion of $48.1 \pm 4.5 \%$ of normal cutaneous values (control, area III, 1 h postoperative). 

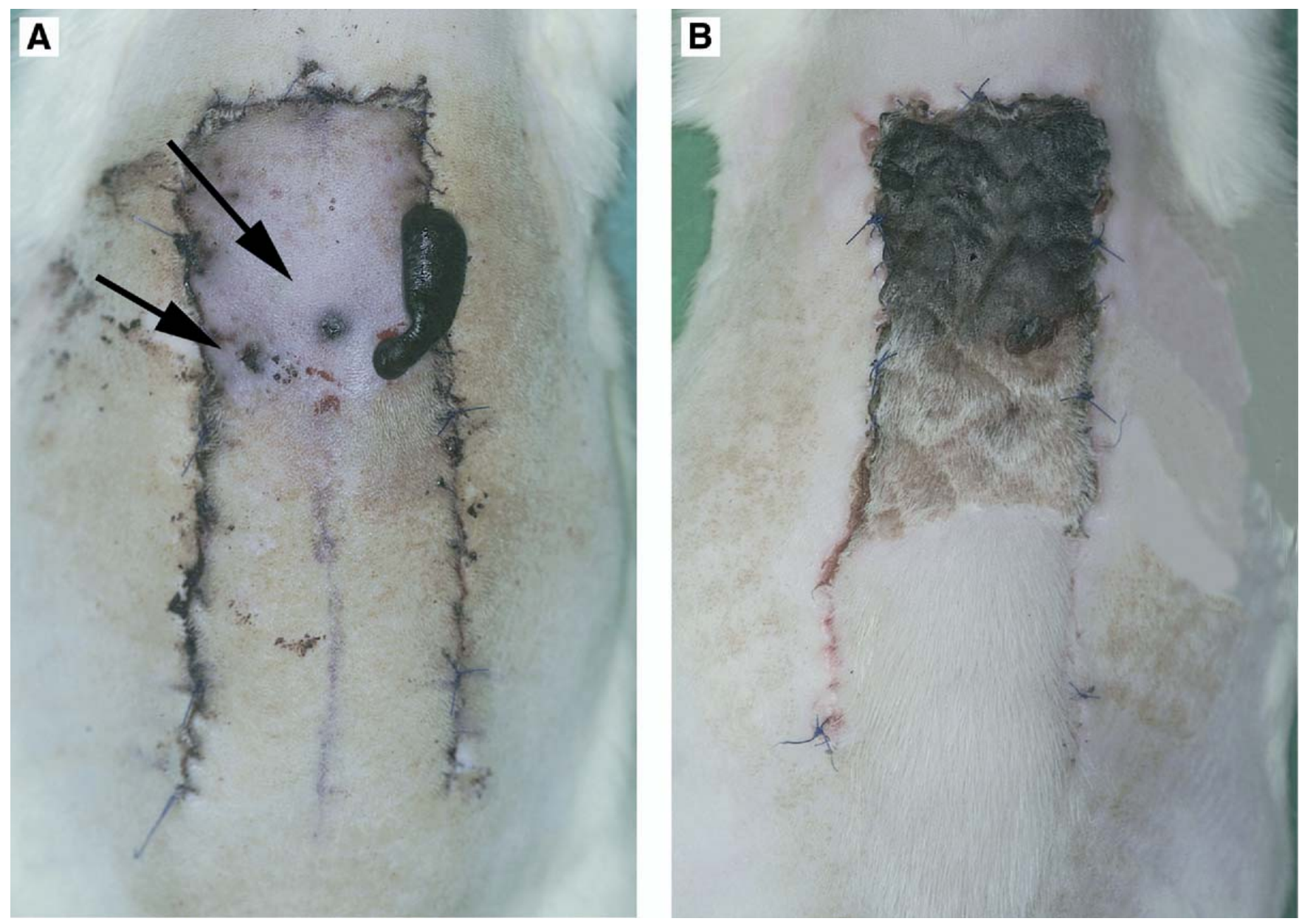

Figure 2: Distal flap necrosis after triple leech application in a random dorsal skin flap at $48 \mathrm{~h}$ postoperatively (right). At 16h postoperatively (left), note the presence of a dark purple color and tissue edema in the distal area III as well as precocious skin necrosis at the site of the leech bite (arrows).

At day 7 after elevation of the random skin flap in the control animals, we observed a flap perfusion of $111.1 \pm 16 \%$ of normal cutaneous values in the proximal area I and of $84.3 \pm 9.3 \%$ of normal skin perfusion in area II. After a single leech application (group 2), Laser-Doppler flowmetry revealed a significant increase in proximal blood flow of $15.6 \%$ at postoperative day 7 (1x leech vs. control: $126.7 \pm 14.9 \%$ vs. $111.1 \pm 16 \%$, respectively) $(\mathrm{p}<0.01)$. In the intermediate area II, we also observed a moderate increase in flap perfusion of $6.9 \%$ (1x leech vs. control: $91.2 \pm 14 \%$ vs. $84.3 \pm 9.3 \%$, respectively) but values did not reach statistical significance $(\mathrm{p}<0.058)$. The triple leech application however, significantly reduced cutaneous perfusion: at postoperative day 7, blood flow in the proximal area I was diminished by $16.1 \%$ (3x leech vs. control: $95 \pm 19.4 \%$ vs. $111.1 \pm 16 \%$, respectively) and in the intermediate area II it was decreased by $13 \%$ ( $3 \mathrm{x}$ leech vs. control: $71.3 \pm 16.6 \%$ vs. $84.3 \pm 9.3 \%$, respectively) $(\mathrm{p}<0.01)$ (figure 5 ). 


\section{Discussion}

Today, it is commonly accepted that the application of leeches is of great benefit in "axial" flaps suffering from venous congestion when normal arterial inflow is maintained. By ingesting blood volumes of $20-60 \mathrm{ml}$ each $(9,27,38)$, leeches provide efficient venous decompression, and thereby maintain the capillary microcirculation until the process of neovascularization has established new venous connections for drainage (39). This has been confirmed by clinical reports of the successful use of leeches for the salvage of pedicled $(28,40,41)$ and free "axial" flaps $(38,42,43)$, as well as in severe venous congestion of replanted digits $(32,33)$ and ears $(26,31)$. However, the effects of the application of leeches in "random" or "randomized axial" flaps suffering from mixed arterio-venous insufficiency have not yet been investigated. Given the probably predominant role of the venous component in mixed arterio-venous insufficiency, we hypothesized that the use of leeches may be an effective means of alleviating venous congestion, restoring minimal perfusion of the capillary bed and thereby increasing flap survival.

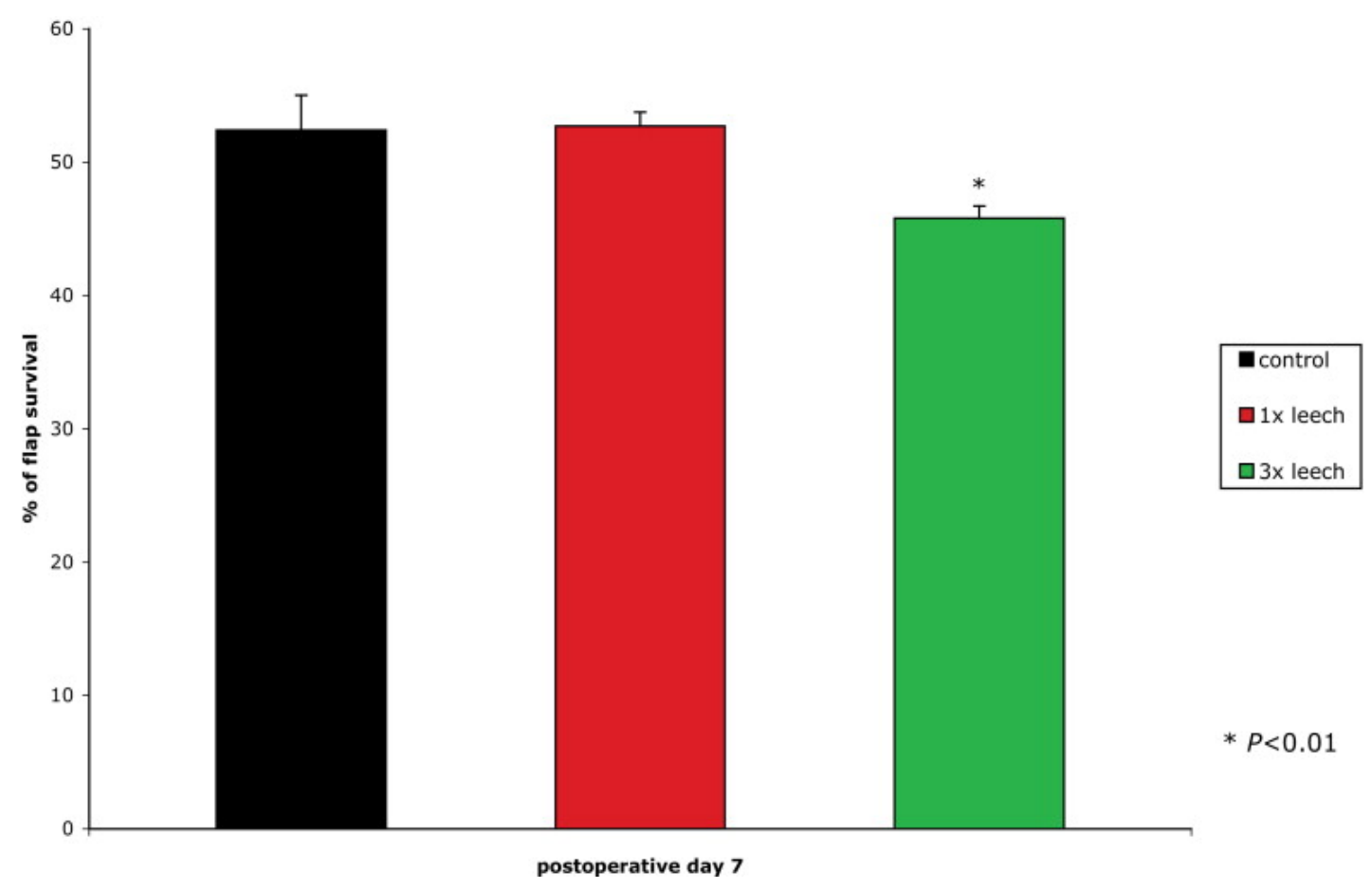

Figure 3: Total flap survival after single and triple application of leeches compared to control animals. Note the significant decrease in flap survival in the triple leech group at postoperative day $7(p<0.01)$. 
Earlier experimental studies in a 3x6cm 'axial' epigastric skin flap in the rat showed a direct correlation of the severity and duration of venous congestion and of the level of arterial perfusion to the volume of the leeches' blood meal and the total ingestion time $(44,45)$ : a prolonged venous congestion of 5-6h already causes slowing of the arterial inflow -a secondary arterial insufficiency - and results in a significantly smaller blood meal as well as an increased ingestion time $(46,47)$. Our animal model resulted in pronounced mixed arterio-venous insufficiency indicated by the presence of severe venous congestion as well as a reduced but maintained arterial blood flow (control, area III, 1h postoperative: 48.1+4.5\%). Even though we did not encounter any problems of leech attachment, which are indicative of complete arterial insufficiency (48), the measured average blood meal of $0.91 \pm 0.17 \mathrm{ml}$ is also clearly inferior to previously reported values and the ingestion time of $72 \pm 22 \mathrm{~min}$ is considerably prolonged. In the present study, we observed that the single leech application induces a transitory beneficial effect on blood flow in the random dorsal skin flap: at postoperative day 2, we measured a significant increase in blood perfusion in the intermediate area II of $15.2 \%(p<0.01)$. This increase, however, progressively diminished to $6.9 \%$ at postoperative day 7 and values did not reach the level of significance $(p<0.058)$. Knowing that improved flap viability can only be achieved by maintaining an increase in perfusion in the critically ischemic intermediate area II, total flap survival at postoperative day 7 consequently remained unchanged. These results differ from the findings by Cottler et al. who observed a significant improvement in both flap survival and blood flow at postoperative day 7 (47) and by Lee et al who confirmed an increase in flap perfusion of $17 \%$ as well as an improved flap survival of $35 \%$ (46). However, both studies investigated the effects of single leech application in an "axial" flap with a temporarily clamped venous pedicle but a maintained arterial inflow and not in a "random" flap suffering from pronounced changes in both arterial and venous blood flow. Triple leech application resulted in pronounced deleterious effects: at postoperative day 2, flap perfusion in the intermediate area II was increased by a mere $2.3 \%$ and values did not reach statistical significance $(p<0.064)$. At postoperative day 7 , however, we measured a statistically significant decrease in blood flow in the intermediate area II of $13 \%$, reflected by a reduction in flap viability of $6.6 \%(p<0.01)$. Clinically, this deleterious hemodynamic effect of triple leech application was visible as the precocious development of distal flap necrosis, starting at the site 


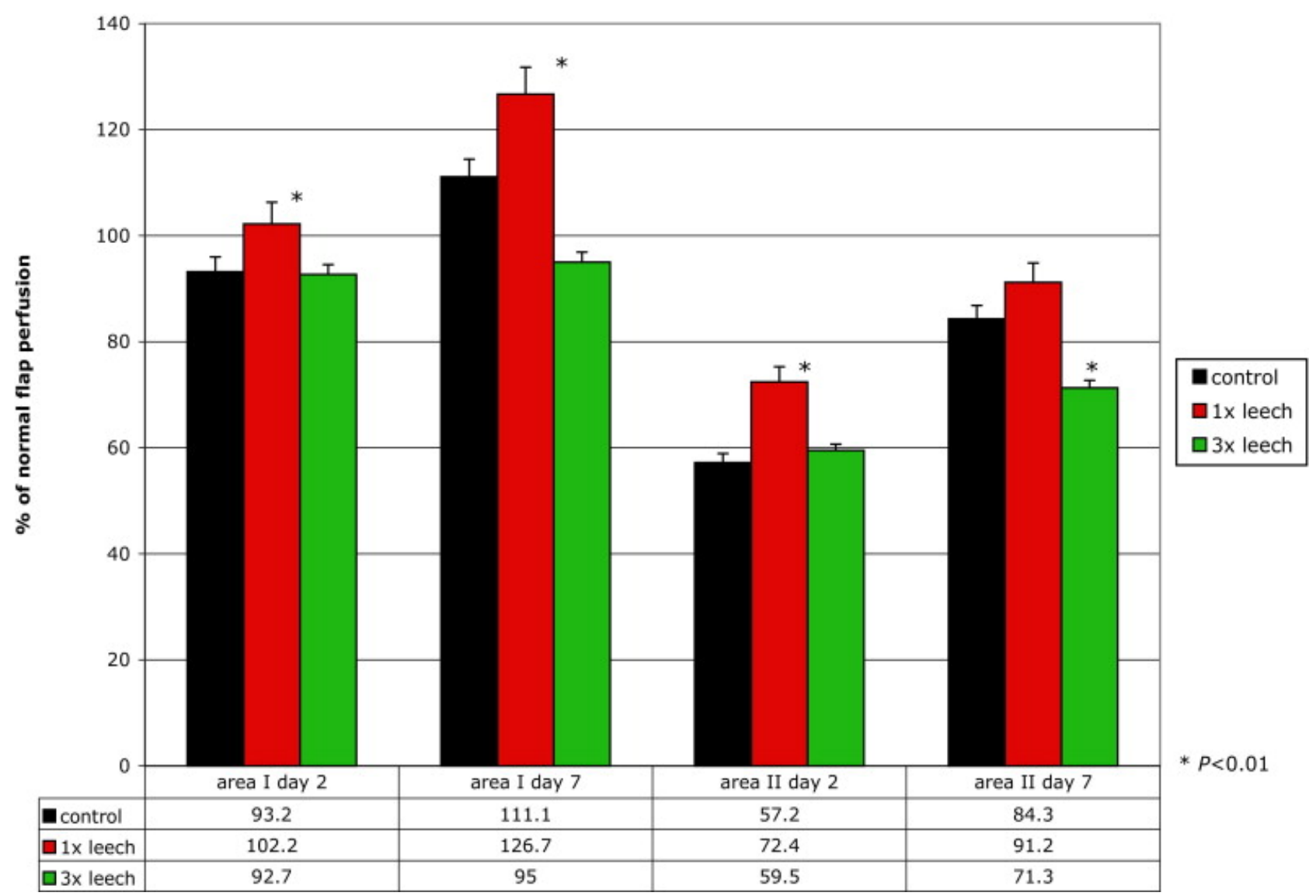

Figure 4: Laser-Doppler flowmetry after single and triple application of leeches and in control animals. In the single leech group, we observed a transitory increase in flap perfusion in intermediate area II at day $2(p<0.01)$ that, however, could not be confirmed on day 7. In the triple leech group, note the absence of any beneficial effects in area II at postoperative day 2 and, especially, the significant decrease in blood flow at postoperative day $7(p<0.01)$.

of the leech bite and complete by postoperative day 2, two days earlier than in the control and single leech group (figure 2). This thus far unknown phenomenon may be explained by a reverse effect of triple leech application: instead of restoring the balance between arterial inflow and venous drainage by alleviating venous congestion (27), triple leech application appears to cause a pronounced withdrawal of both venous and arterial blood. This results in a significant decrease in arterial perfusion in the surroundings of the leech bite, further enhancing local ischemia and finally causing tissue necrosis in random skin flaps.

We conclude that: 1) the use of leeches in mixed arterio-venous insufficiency results in deleterious effects on local blood perfusion and reduces total survival of ischemic random skin flaps in the rat; 2) a thorough clinical evaluation of the nature of the vascular insufficiency is mandatory before the use of leeches and needs to exclude obvious arterial but also mixed 
arterio-venous insufficiency; 3) the frequency and number of leeches applied as well as the duration of application have to be adapted to the degree of venous insufficiency and the size of the flap; and 4) pure venous congestion with maintenance of arterial supply remains the only indication for controlled leech application in the clinical setting.

\section{ACKNOWLEDGMENTS}

We are grateful to C. Di Sanza and M. Quayzin for technical assistance and informed discussion.

\section{GRANTS}

This study was supported by grants from the Swiss National Science Foundation: grant no: $3200-067254.01$ to B. Pittet and grant no: 3100-064037.00 to M.S. Pepper. 


\section{REFERENCES}

1. Bunkis, J., Mulliken, J. B., Upton, J., and Murray, J. E. The evolution of techniques for reconstruction of full-thickness cheek defects. Plast Reconstr Surg 70: 319-327, 1982.

2. Kulakowski, A., and Towpik, E. Reconstruction of full-thickness cheek defects after cancer surgery. Eur J Surg Oncol 13: 57-62, 1987.

3. Baker, S. R. Regional flaps in facial reconstruction. Otolaryngol Clin North Am 23: 925946, 1990.

4. Wheeland, R. G. Reconstruction of the lower lip and chin using local and random-pattern flaps. J Dermatol Surg Oncol 17: 605-615, 1991.

5. Alizadeh, N., Pittet, B., Tenorio, X., Pyke, C., Baetens, D., Schlaudraff, K. U., Montandon, D., Ezban, M., and Pepper, M. S. Active-site inactivated FVIla decreases thrombosis and necrosis in a random skin flap model of acute ischemia. J Surg Res 122: 263-273, 2004.

6. Soucacos, P. N., Beris, A. E., Malizos, K. N., Kabani, C. T., and Pakos, S. The use of medicinal leeches, Hirudo medicinalis, to restore venous circulation in trauma and reconstructive microsurgery. Int Angiol 13: 251-258, 1994.

7. Summer, D. Diagnosis of deep venous thrombosis. In R. Rutherford (Ed.), Vascular Surgery. Philadelphia: WB. Saunders, 1995. Pp. 1704-1709.

8. Weinfeld, A. B., Yuksel, E., Boutros, S., Gura, D. H., Akyurek, M., and Friedman, J. D. Clinical and scientific considerations in leech therapy for the management of acute venous congestion: an updated review. Ann Plast Surg 45: 207-212, 2000.

9. Kraemer, B. A., Korber, K. E., Aquino, T. I., and Engleman, A. Use of leeches in plastic and reconstructive surgery: a review. J Reconstr Microsurg 4: 381-386, 1988.

10. O'Hara, M. M. Beauty and the beast: nursing care of the patient undergoing leech therapy. Plast Surg Nurs 11: 101-104, 1991.

11. Whitaker, I. S., Izadi, D., Oliver, D. W., Monteath, G., and Butler, P. E. Hirudo Medicinalis and the plastic surgeon. Br J Plast Surg 57: 348-353, 2004.

12. Bhishagratna, K. K. An English translation of the sushruta samhitu based on original Sanskrit text. Varanasi, India: Vidya Vidas Press, 1963.

13. Lent, C. New medical and scientific uses of the leech. Nature 323: 494, 1986.

14. Whitaker, I. S., Rao, J., Izadi, D., and Butler, P. E. Historical Article: Hirudo medicinalis: ancient origins of, and trends in the use of medicinal leeches throughout history. $\mathrm{Br} \mathrm{J}$ Oral Maxillofac Surg 42: 133-137, 2004. 
15. Dieffenbach, J. Chirurgische Erfahrungen besonders über die Wiederherstellung Zerstörter Theile des menslichen Körpers nach neuen Methoden. Berlin: T.C.F. Enslin, 1829-1834.

16. King, L. S. The blood-letting controversy: a study in the scientific method. Bull Hist Med 35: 1-13, 1961.

17. Makin, C. A., and Edwards, L. Application of leeches to reduce swelling after reconstructive surgery. Br J Urol 59: 189, 1987.

18. Sawyer, R. T. Johann Friedrich Dieffenbach: successful use of leeches in plastic surgery in the 1820s. Br J Plast Surg 53: 245-247, 2000.

19. Abdelgabar, A. M., and Bhowmick, B. K. The return of the leech. Int J Clin Pract 57: 103105, 2003.

20. Utley, D. S., Koch, R. J., and Goode, R. L. The failing flap in facial plastic and reconstructive surgery: role of the medicinal leech. Laryngoscope 108: 1129-1135, 1998.

21. Sawyer, R. T. Thrombolytics and anti-coagulants from leeches. Biotechnology ( $N$ Y $) 9$ : 513-515, 518, 1991.

22. Salzet, M. Leech thrombin inhibitors. Curr Pharm Des 8: 493-503, 2002.

23. Sawyer, R. T. Leech biology and behaviour. New York: Oxford University Press, 1986.

24. Whitaker, I. S., Cheung, C. K., Chahal, C. A., Karoo, R. O., Gulati, A., and Foo, I. T. By what mechanism do leeches help to salvage ischaemic tissues? A review. Br J Oral Maxillofac Surg 43: 155-160, 2005.

25. Wells, M. D., Manktelow, R. T., Boyd, J. B., and Bowen, V. The medical leech: an old treatment revisited. Microsurgery 14: 183-186, 1993.

26. Anthony, J. P., Lineaweaver, W. C., Davis, J. W., Jr., and Buncke, H. J. Quantitative fluorimetric effects of leeching on a replanted ear. Microsurgery 10: 167-169, 1989.

27. Hayden, R. E., Phillips, J. G., and McLear, P. W. Leeches. Objective monitoring of altered perfusion in congested flaps. Arch Otolaryngol Head Neck Surg 114: 1395-1399, 1988.

28. Rao, J., and Whitaker, I. S. Use of Hirudo medicinalis by maxillofacial surgical units in the United Kingdom: current views and practice. Br J Oral Maxillofac Surg 41: 54-55, 2003.

29. Soucacos, P. N., Beris, A. E., Malizos, K. N., Xenakis, T. A., and Georgoulis, A. Successful treatment of venous congestion in free skin flaps using medical leeches. Microsurgery 15: 496-501, 1994.

30. Nath, R. K., Kraemer, B. A., and Azizzadeh, A. Complete ear replantation without venous anastomosis. Microsurgery 18: 282-285, 1998. 
31. Mutimer, K. L., Banis, J. C., and Upton, J. Microsurgical reattachment of totally amputated ears. Plast Reconstr Surg 79: 535-541, 1987.

32. Brody, G. A., Maloney, W. J., and Hentz, V. R. Digit replantation applying the leech Hirudo medicinalis. Clin Orthop: 133-137, 1989.

33. Foucher, G., Henderson, H., and Maneau, M. Distal digital replantation: one of the best indications for microsurgery. Int. J. Microsurg 3: 263-270, 1981.

34. McFarlane, R. M., Deyoung, G., and Henry, R. A. The Design of a Pedicle Flap in the Rat to Study Necrosis and Its Prevention. Plast Reconstr Surg 35: 177-182, 1965.

35. Rinsch, C., Quinodoz, P., Pittet, B., Alizadeh, N., Baetens, D., Montandon, D., Aebischer, P., and Pepper, M. S. Delivery of FGF-2 but not VEGF by encapsulated genetically engineered myoblasts improves survival and vascularization in a model of acute skin flap ischemia. Gene Ther 8: 523-533, 2001.

36. Mandriota, S. J., Pyke, C., Di Sanza, C., Quinodoz, P., Pittet, B., and Pepper, M. S. Hypoxia-inducible angiopoietin-2 expression is mimicked by iodonium compounds and occurs in the rat brain and skin in response to systemic hypoxia and tissue ischemia. $\mathrm{Am}$ J Pathol 156: 2077-2089, 2000.

37. Conforti, M. L., Connor, N. P., Heisey, D. M., and Hartig, G. K. Evaluation of performance characteristics of the medicinal leech (Hirudo medicinalis) for the treatment of venous congestion. Plast Reconstr Surg 109: 228-235, 2002.

38. Rao, P., Bailie, F. B., and Bailey, B. N. Leechmania in microsurgery. Practitioner 229: 901-905, 1985.

39. de Chalain, T., and Jones, G. Replantation of the avulsed pinna: 100 percent survival with a single arterial anastomosis and substitution of leeches for a venous anastomosis. Plast Reconstr Surg 95: 1275-1279, 1995.

40. Derganc, M., and Zdravic, F. Venous congestion of flaps treated by application of leeches. Br J Plast Surg 13: 187-192, 1960.

41. Batchelor, A. G., Davison, P., and Sully, L. The salvage of congested skin flaps by the application of leeches. Br J Plast Surg 37: 358-360, 1984.

42. Lim, C. L. Successful transfer of "free" microvascular superficial temporal artery flap with no obvious venous drainage and use of leeches for reducing venous congestion: case report. Microsurgery 7: 87-88, 1986.

43. Henderson, H. P., Matti, B., Laing, A. G., Morelli, S., and Sully, L. Avulsion of the scalp treated by microvascular repair: the use of leeches for post-operative decongestion. $\mathrm{Br} J$ Plast Surg 36: 235-239, 1983. 
44. Smoot, E. C., 3rd, Debs, N., Banducci, D., Poole, M., and Roth, A. Leech therapy and bleeding wound techniques to relieve venous congestion. J Reconstr Microsurg 6: 245250, 1990.

45. Smoot, E. C., Ruiz-Inchaustegui, J. A., and Roth, A. C. Mechanical leech therapy to relieve venous congestion. J Reconstr Microsurg 11: 51-55, 1995.

46. Lee, C., Mehran, R. J., Lessard, M. L., and Kerrigan, C. L. Leeches: controlled trial in venous compromised rat epigastric flaps. Br J Plast Surg 45: 235-238, 1992.

47. Cottler, P. S., Gampper, T. J., Rodeheaver, G. T., and Skalak, T. C. Evaluation of clinically applicable exsanguination treatments to alleviate venous congestion in an animal skin flap model. Wound Repair Regen 7: 187-195, 1999.

48. Lent, C. M., Fliegner, K. H., Freedman, E., and Dickinson, M. H. Ingestive behaviour and physiology of the medicinal leech. J Exp Biol 137: 513-527, 1988. 